Review

\title{
Secreted Protein Acidic and Rich in Cysteine: Metabolic and Homeostatic Properties beyond the Extracellular Matrix Structure
}

\author{
Abdelaziz Ghanemi ${ }^{1,2}$, Mayumi Yoshioka ${ }^{2}$ and Jonny St-Amand ${ }^{1,2, *}$ \\ 1 Department of Molecular Medicine, Faculty of Medicine, Laval University, Québec, QC G1V 0A6, Canada; \\ abdelaziz.Ghanemi@crchudequebec.ulaval.ca \\ 2 Functional Genomics Laboratory, Endocrinology and Nephrology Axis, CHU de Québec-Université Laval \\ Research Center, Québec, QC G1V 4G2, Canada; mayumi.yoshioka@crchudequebec.ulaval.ca \\ * Correspondence: jonny.st-amand@crchudequebec.ulaval.ca; Tel.: +(418)-654-2296
}

Received: 15 January 2020; Accepted: 29 March 2020; Published: 1 April 2020

check for updates

\begin{abstract}
An extracellular matrix (ECM) is a network of numerous macromolecules that represents the cellular structural support involved in key biofunctions such as signal transduction and cellular adhesion. In addition, ECM-associated proteins interact with ECM and with other endogenous structures and molecules to control cellular growth, structural modifications, cellular migration, etc. Among the ECM-associated proteins, secreted protein acidic and rich in cysteine (SPARC) is a protein that is known to be expressed when tissues change. Herein, we put a spotlight on selected, metabolic and homeostatic properties beyond the known properties of ECM and SPARC. Importantly, the synchronization of the metabolic and structural implications of SPARC and the ECM would indicate an adaptation of the metabolism to meet the needs of the changes that the tissues undergo. Highlighting such properties would have important applications in diverse fields that include therapeutics, metabolics, and pathogenesis.
\end{abstract}

Keywords: secreted protein acidic and rich in cysteine; extracellular matrix; metabolism; homeostasis

\section{Extracellular Matrix (ECM) and Secreted Protein Acidic and Rich in Cysteine (SPARC)}

The increasing number of pathologies involving structural or functional abnormalities, combined with the lack of organ donors, has made developing novel approaches in regenerative medicine a necessity. Recent advances in regenerative medicine have brought a lot of hope for tissue engineering, as shown by clinical trials that use stem cells (both somatic and embryonic and even adipose-derived stem cells) in therapeutic applications [1-3]. Within the context of regenerative medicine, the ECM is implicated in a variety of processes that include cellular repair and regeneration, remodeling [4], and intercellular communication [5] (Figure 1). Therefore, ECM products, including hydrogels [5], have been used or suggested in clinical practice [6,7]. Such applications derive from the structural and functional properties of the ECM and its associated proteins. Thus, further understanding these properties could expand the applications in regenerative medicine as well as in fields such as pharmacology and in vitro researches. 


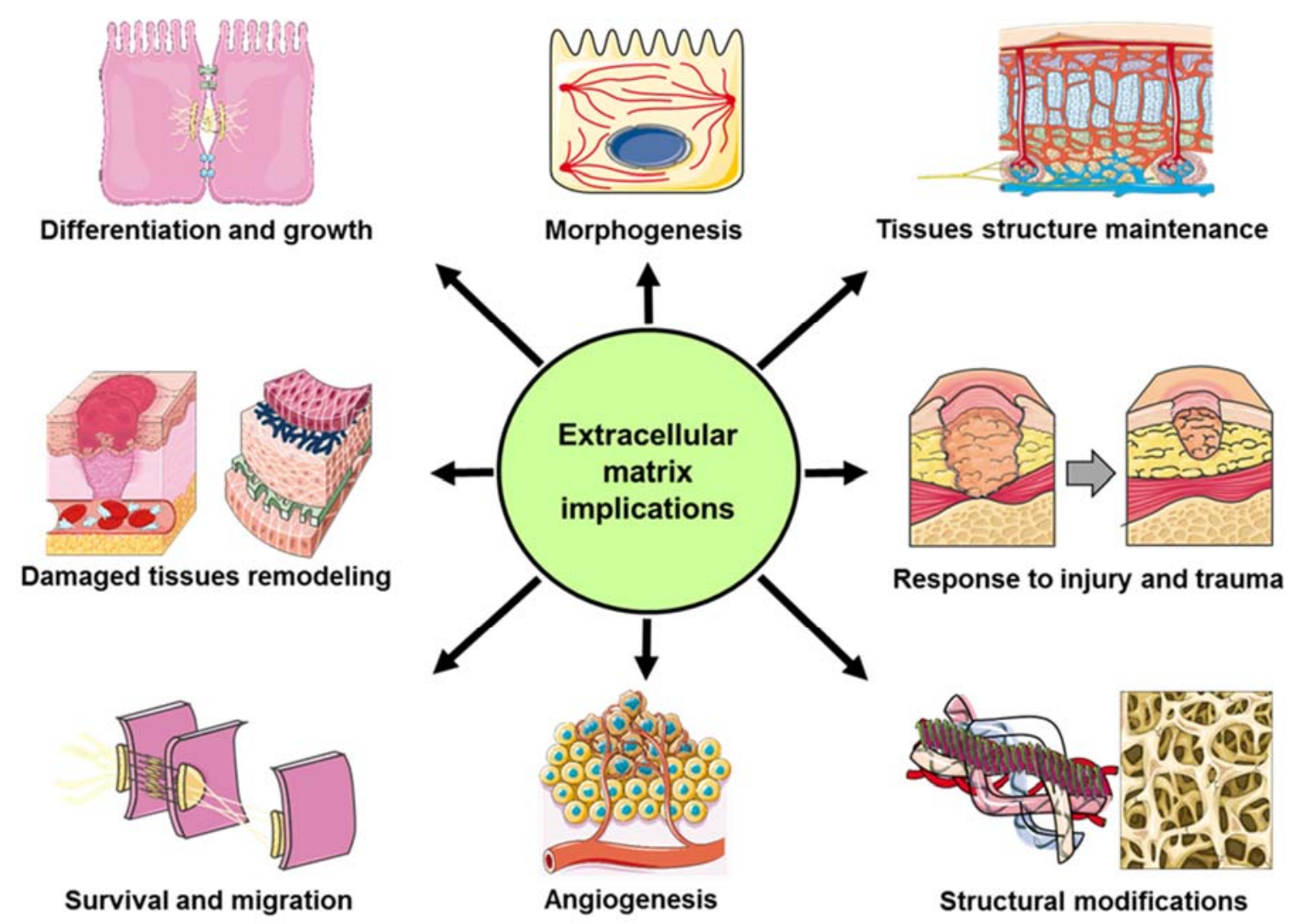

Figure 1. Example of extracellular matrix (ECM) implications. The extracellular matrix is involved in a variety of biological functions, mainly but not only during tissue development under physiological and pathological conditions.

ECM is a three-dimensional network surrounding cells, and is made of different macromolecules, including collagens, elastins, proteoglycans/glycosaminoglycans, laminins, and fibronectins $[5,8]$. It governs a variety of biological functions such as cellular differentiation, growth, survival, migration, homeostasis, and morphogenesis [8]. ECM remodeling through its components is crucial in both physiology and pathology [9-11]. Such remodeling is controlled by epigenetics through the dynamic cellular environment ( $\mathrm{pH}$, cytokines, etc. [12]) that induces gene expression modulations [9] towards a modified proteomic profile required for remodeling. On the other hand, the proteins associated with the ECM structurally and functionally complete the molecular network surrounding the cells and governing tissue properties. Herein, we mention the SPARC that represents an example of an ECM-associated protein expressed, mainly when tissues change $[13,14]$, indicating its particular importance during tissue remodeling and suggesting its close interaction with the ECM during such a process. SPARC (also known as BM-40 or osteonectin) is a glycoprotein with a molecular weight of $32 \mathrm{kDa}$ [15] encoded by a highly conserved single gene [16], which reflects the evolutionary importance of this gene. It has a single polypeptide chain [17], and its human-matured version has 286 amino acid residues [18]. This glycoprotein is made of three domains (N-terminal domain, C-terminal domain, and a domain characterized by a follistatin-like domain) [19]. The three domains provide SPARC with its biophysical and biochemical properties such as $\mathrm{Ca}^{2+}$-binding, protease inhibitor, and collagen binding [19]. These properties allow SPARC to bind to both collagen and hydroxyapatite [13]. This binding ability is illustrated by studies showing that collagen I and SPARC are both reduced by valproate treatment in cultured bone cells [20], the implication of SPARC in stromal mineralization, as well as the adhesion of both osteoblasts and platelets to the ECM [21]. In fact, SPARC was first discovered in bones [18] and shown to be highly important in osteogenesis [17]. It is also the most expressed in the bone compared to the other noncollagenous polypeptides [22]. SPARC was initially 
named osteonectin following its discovery in bones, and was even thought to be bone-specific $[13,23]$ before it was shown to be expressed in most tissues.

Beyond the structural implications of SPARC and ECM, it remains important to clarify their metabolic and homeostatic properties under different circumstances. Indeed, the increasing importance of ECM implications and applications in biological research and clinical practice [24-26] makes exploring the ECM metabolic aspects important in order to uncover novel roles or identify new possible applications for ECM. For instance, among the ECM's current applications we mention is the use of ECM bioscaffolds (decellularized) in clinical tissue remodeling [6] to enhance the functional reconstruction of injured tissues (muscle, esophagus, etc.) rather than develop scar tissues at the end of the healing process of these tissues [7]. It is worth mentioning that ischemic injuries have been treated using ECM hydrogels [26]. Moreover, these hydrogels are also used to study the ECM effects on culture [4] as well as to mimic tumor microenvironments [12].

Elucidating such concepts would both deepen our knowledge of metabolics and uncover unknown effects of regenerative medicine approaches. Understating how ECM and its associated proteins impact aspects beyond structures such as metabolism and cellular biochemistry could lead to the development of novel therapies or optimize those currently available. Furthermore, expanding the field of investigation beyond the ECM to include the biomolecules associated to the ECM would provide a wider understanding of the noncellular entities of tissues within the context of metabolics, biochemical homeostasis, and energy balance. SPARC represents an illustration of this concept. It is not only involved in tissue response to injury and cellular differentiation [27] but can also shape some metabolic patterns, as described below.

\section{SPARC: Metabolics and Homeostasis}

Both ECM and the proteins associated with it have the ability to interact between them as well as with cells, other active molecules, and cell receptors under diverse physiological and pathological conditions [28-31]. The ECM and its associated proteins represent the frame into which cells reside and upon which key tissue properties depend. Indeed, what provides tissue with its nature (hard, soft, etc.) and properties is governed by the cellular adhesion of cells constituting that tissue and their interactions through the ECM and its associated proteins. This explains the need for ECM remodeling and changes to adapt to new physiological or pathological conditions [32]. Furthermore, the content in other elements like calcium does impact the tissue nature and illustrates this concept as well. For instance, bones are known to be of a hard nature, and this is due to their rich content in calcium. Within this context, SPARC binds to both hydroxyapatite and collagen in a bone matrix $[13,33,34]$, which strengthens the bone hardness. Therefore, the bone content in both SPARC and calcium and the binding ability these two components have would govern the strength and hardness of bones depending on how strong the adhesion is between osteocytes, their ECM, hydroxyapatite, and ECM-associated proteins (SPARC in the current example).

Regarding the energy metabolism pattern, the two components of energy balance are energy storage and energy expenditure. The storage is mainly in the form of lipids in adipocytes, whereas the energy expenditure is governed by the muscle's energy usage (both resting metabolic rate and physical activity). As we have described in a recent paper [15], the ability of certain cells like adipocytes to expend would depend on the ECM's "rigidity", which would—in part—depend upon SPARC expression. Indeed, due to the interaction between SPARC and collagen, a deficiency in SPARC (such as in a Sparc knock-out organism) would reduce collagen maturity and weaken the ECM structure, thereby reducing the ECM rigidity. ECM rigidity is defined by how strong the adhesion is between ECM and its associated protein and whether this adhesion would limit the cellular expansion of these cells surrounded by such an "elastic" or a "rigid" ECM [15]. Following this line of thought, how rigid the ECM of adipocyte is would govern whether the adiposity's development would be towards hyperplasia or hypertrophy. Whereas adipocyte's expansion would result from an "elastic" ECM, a "rigid" ECM would limit such expansion and rather direct the adiposity's development towards 
hyperplasia [15]. This results in different forms of adiposity distribution, which is mainly towards either subcutaneous or visceral fat accumulation. These metabolic outcomes control the metabolic phenotype [35-37], as well as morbidities and pathological complications [38] seen among different individuals with obesity. Studies on SPARC highlight its numerous metabolic implications, including energy metabolism in the skeletal muscle [15] and adiposity control [39] (Figure 2).

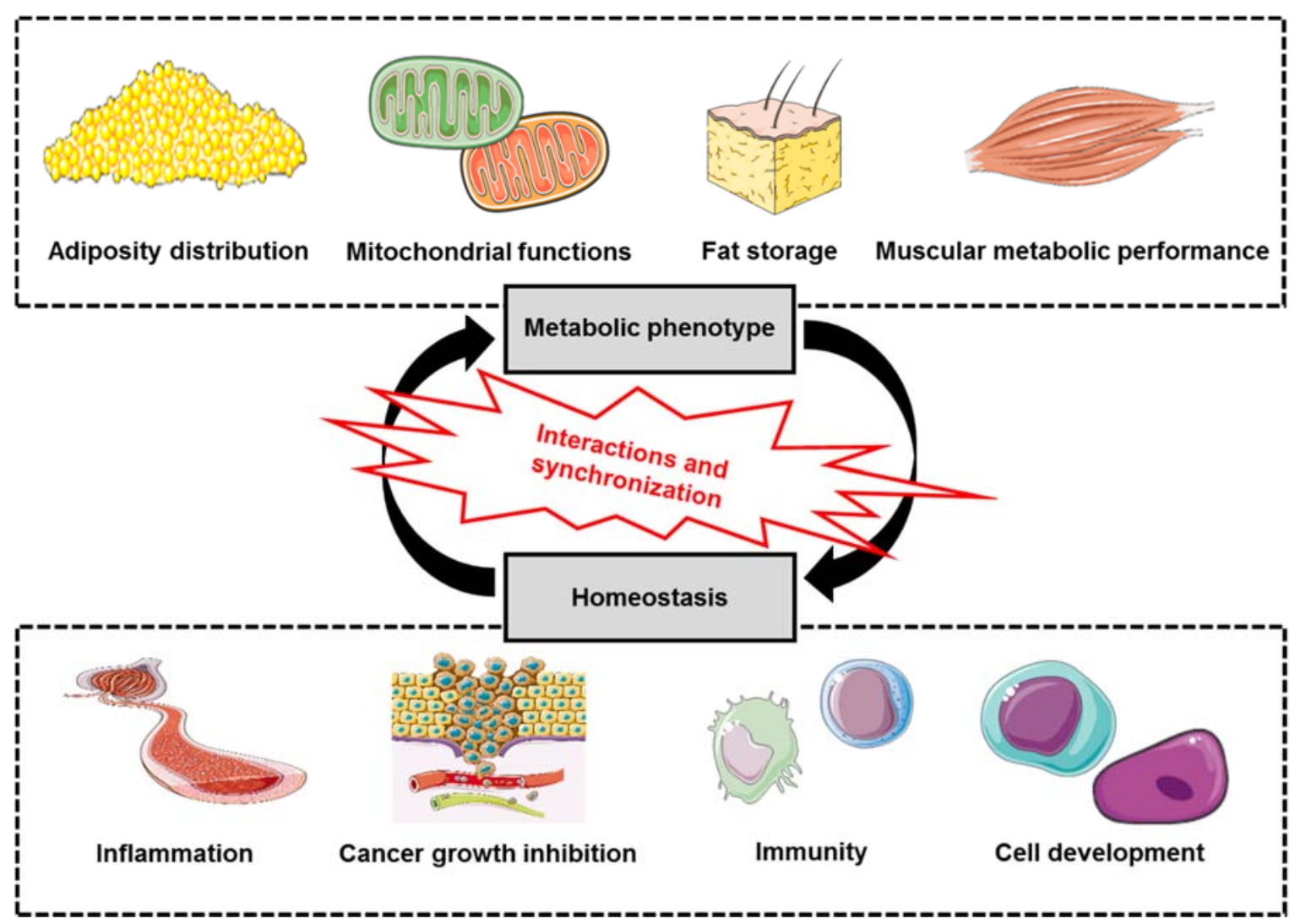

Figure 2. Secreted protein acidic and rich in cysteine (SPARC) metabolic and homeostatic implications. SPARC is involved in a variety of metabolic as well as homeostatic processes in diverse tissues, which suggest that SPARC simultaneously interacts with metabolism and homeostasis in order to synchronize with both of them.

Regarding the impact that ECM has on muscles, studies conducted on elderly men have shown that endurance training increased the expression of gene coding for both ECM proteins and SPARC in the skeletal muscles, and also genes related to metabolic functions such as oxidative phosphorylation (OXPHOS) [40]. Such results show a potential implication of SPARC in exercise-induced metabolic benefits depending on how strongly the Sparc gene is expressed or knocked-out as we have previously described [15]. Herein, the differential expression of genes related to the ECM indicates a potential role of the ECM (and eventually ECM-associated proteins such as SPARC) within the muscular metabolic performance seen after training compared to the baseline. In addition, there is a possible link between the ECM and the mitochondrial function [41], which reflects other possible metabolic implications. At the molecular level, studies indicated how ECM (or its remodeling) regulates lipid metabolism [42] and glucose metabolism [43]. Moreover, the ECM-associated protein SPARC has been shown to be implicated in the regulation of the glucose transporter type 4 expression (controlling the glucose uptake) [44]. All these elements show how targeting the ECM or its associated proteins could impact the energy balance and the metabolic paths. Fortunately, cellular and animal models, including those of the knock-out of Sparc, shed light on the roles the ECM and its associated proteins (such as collagen) 
have within different contexts [45-48]. These data will contribute to further mapping the metabolic puzzle related to the ECM and its associated proteins.

More importantly, the implications of SPARC and the ECM in both metabolism and functions like growth, differentiation, and morphogenesis could indicate that the ECM and SPARC might synchronize diverse cellular functions so that the metabolic needs meet the biological changes the tissues undergo (Figures 2 and 3). This means that the ECM remodeling and SPARC expression would simultaneously impact parameters such as cell growth and differentiation as well as metabolic and other homeostatic patterns. This would result in a cellular profile adapted to the changes that tissues undergo in terms of energy usage and storage and homeostatic needs. Moreover, the implications of the ECM [46] or SPARC [49-52] in other nonstructural functions such as inflammation, immunity, and cell growth would not only emphasize the importance of uncovering more pathways that ECM and SPARC govern but would also strengthen knowledge of metabolics, especially of links that have been established between cytokine (involved in inflammation and immunity) and metabolism [53-55]. Herein, cancer would be an illustrative example of such a "cell development-metabolism synchronization". Indeed, whereas cancer represents a status in which ECM remodeling is required and observed [56-58], cancer cells and the tumor microenvironment have specific metabolic profiles and unique bioenergetic properties in different form noncancer cells $[59,60]$. Interestingly, SPARC was suggested to play a homeostasis-regulatory role in cancer. More precisely, while SPARC is overexpressed during cancer development, it inhibits tumor growth without inducing apoptosis in normal cells (selective inhibition), indicating a possible feedback effect towards a homeostatic regulation of cell growth in the context of cancer [61]. This regulatory role does not seem to be limited to development but would also control the metabolic profile of the tumoral cells in order to reach a balance/synchronization of both the structural changes and the metabolic needs.

\section{Perspective and Implications}

These selected examples show numerous metabolic and homeostatic implications of both SPARC and ECM at different levels, from cellular metabolism of glucose and lipids to both energy usage (muscles) and energy storage (adipocytes), as well as fat distribution pattern. It reflects how those biomolecules that form a three-dimensional network could be a starting point either to develop novel therapies or to optimize existing treatments for obesity and other metabolic disorders. Importantly, such concepts would also have applications in tissue engineering and regenerative medicine, including stem cell research [62].

Extracellular matrix changes induce cellular adaptation, which leads to structural and metabolic modifications in the tissues and organs. This metabolic-structural synchronization could suggest an adaptation of the metabolism to meet the energy needs of the changes that the tissues undergo. Elucidating such metabolic-structural synchronization between the metabolism and the structural changes would produce diverse perspectives along with a verity of applications in numerous fields, including therapeutics, cell culture, pathogenesis, and regenerative medicine.

Indeed, putting a spotlight on these nonstructural implications of the ECM and SPARC (as an example of an ECM-associated protein) such as the metabolic properties and growth homeostasis would allow us to predict (and potentially reverse) the "metabolic side effects" and the side effects related to immunity, inflammation, and cell growth of interventions targeting or interacting with matricellular proteins within the context of regenerative medicine [63]. Moreover, since metabolic changes are not limited to energy balance but can also involve drug metabolism, this would expend the implications to the context of pharmacovigilance, among other concepts.

In conclusion, we emphasize the importance of further investigations towards uncovering how SPARC, ECM, and the other ECM-associated proteins can impact (and be influenced by) diverse cellular metabolic, biochemical, and homeostatic pathways. Such discoveries will lead to novel yet important applications in a variety of fields, including therapeutics, pathogenesis, metabolics, and regenerative medicine (Figure 3). 

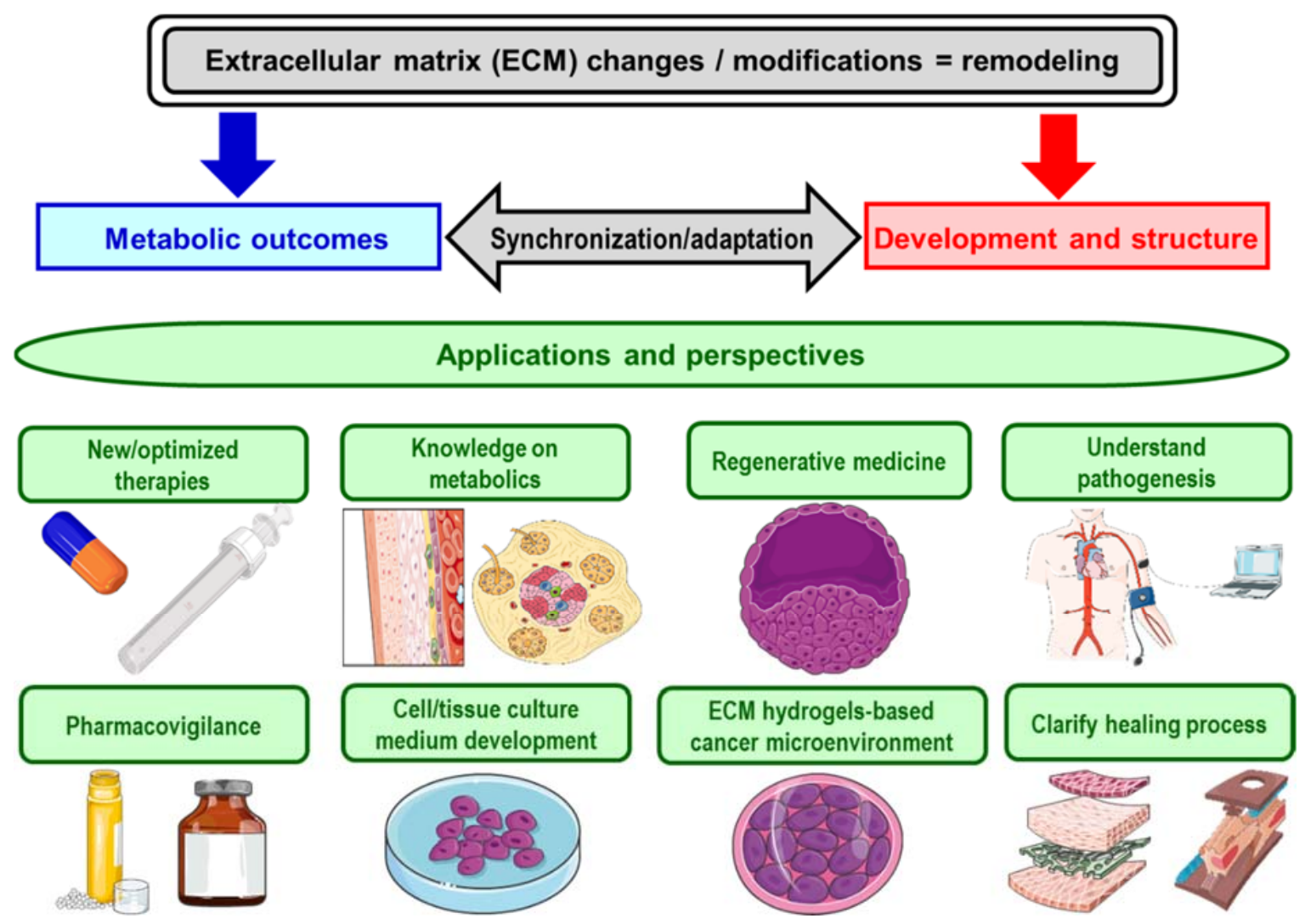

Figure 3. Metabolic-structural synchronization of the extracellular matrix properties.

Funding: This research received no external funding.

Acknowledgments: Abdelaziz Ghanemi is a recipient of a Merit scholarship program for foreign students from the Ministry of Education and Higher Education of Quebec, Canada, The Fonds de recherche du Québec-Nature et technologies (FRQNT) is responsible for managing the program (Bourses d'excellence pour étudiants étrangers du Ministère de l'Éducation et de l'Enseignement supérieur du Québec, Le Fonds de recherche du Québec-Nature et technologies (FRQNT) est responsable de la gestion du programme). The figures were created using images from: http://smart.servier.com. Servier Medical Art by Servier is licensed under a Creative Commons Attribution 3.0 Unported License.

Conflicts of Interest: The authors declare no conflict of interest.

\section{References}

1. Riazi, A.M.; Kwon, S.Y.; Stanford, W.L. Stem Cell Sources for Regenerative Medicine. Adv. Struct. Saf. Stud. 2009, 482, 55-90.

2. Mizuno, H. Adipose-derived stem and stromal cells for cell-based therapy: Current status of preclinical studies and clinical trials. Curr. Opin. Mol. Ther. 2010, 12, 442-449.

3. Aboushwareb, T.; Atala, A. Stem cells in urology. Nat. Clin. Pract. Urol. 2008, 5, 621-631. [CrossRef]

4. Horton, E.R.; Vallmajo-Martin, Q.; Martin, I.; Snedeker, J.G.; Ehrbar, M.; Blache, U. Extracellular Matrix Production by Mesenchymal Stromal Cells in Hydrogels Facilitates Cell Spreading and Is Inhibited by FGF-2. Adv. Heal. Mater. 2020, 1901669. [CrossRef] [PubMed]

5. Geckil, H.; Xu, F.; Zhang, X.; Moon, S.; Demirci, U. Engineering hydrogels as extracellular matrix mimics. Nanomedicine 2010, 5, 469-484. [CrossRef] [PubMed]

6. Saldin, L.T.; Cramer, M.C.; Velankar, S.S.; White, L.; Badylak, S.F. Extracellular matrix hydrogels from decellularized tissues: Structure and function. Acta Biomater. 2017, 49, 1-15. [CrossRef] [PubMed]

7. Swinehart, I.T.; Badylak, S.F. Extracellular matrix bioscaffolds in tissue remodeling and morphogenesis. Dev. Dyn. 2016, 245, 351-360. [CrossRef] 
8. Theocharis, A.D.; Skandalis, S.S.; Gialeli, C.; Karamanos, N.K. Extracellular matrix structure. Adv. Drug Deliv. Rev. 2016, 97, 4-27. [CrossRef]

9. Vigetti, D.; Viola, M.; Karousou, E.; Deleonibus, S.; Karamanou, K.; De Luca, G.; Passi, A. Epigenetics in extracellular matrix remodeling and hyaluronan metabolism. FEBS J. 2014, 281, 4980-4992. [CrossRef]

10. Sonbol, H.S. Extracellular Matrix Remodeling in Human Disease. J. Microsc. Ultrastruct. 2018, 6, $123-128$. [CrossRef]

11. Rauch, U. Extracellular matrix components associated with remodeling processes in brain. Cell. Mol. Life Sci. 2004, 61, 2031-2045. [CrossRef] [PubMed]

12. Park, K.M.; Lewis, D.; Gerecht, S. Bioinspired Hydrogels to Engineer Cancer Microenvironments. Annu. Rev. Biomed. Eng. 2017, 19, 109-133. [CrossRef] [PubMed]

13. Termine, J.D.; Kleinman, H.K.; Whitson, S.; Conn, K.M.; McGarvey, M.L.; Martin, G.R. Osteonectin, a bone-specific protein linking mineral to collagen. Cell 1981, 26, 99-105. [CrossRef]

14. Bradshaw, A.D. The role of SPARC in extracellular matrix assembly. J. Cell Commun. Signal. 2009, 3, $239-246$. [CrossRef] [PubMed]

15. Ghanemi, A.; Melouane, A.; Yoshioka, M.; St-Amand, J. Secreted protein acidic and rich in cysteine and bioenergetics: Extracellular matrix, adipocytes remodeling and skeletal muscle metabolism. Int. J. Biochem. Cell Boil. 2019, 117, 105627. [CrossRef]

16. Kelleher, C.M.; McLean, S.; Mecham, R.P. Vascular Extracellular Matrix and Aortic Development, in Current Topics in Developmental Biology; Academic Press: Cambridge, MA, USA, 2004; pp. 153-188.

17. Maeda, H.; Wada, N.; Tomokiyo, A.; Monnouchi, S.; Akamine, A. Chapter Six-Prospective Potency of TGF- $\beta 1$ on Maintenance and Regeneration of Periodontal Tissue, in International Review of Cell and Molecular Biology; Jeon, K.W., Ed.; Academic Press: Cambridge, MA, USA, 2013; pp. 283-367.

18. McKee, D.M.; Cole, W.G. Chapter 2-Bone Matrix and Mineralization, in Pediatric Bone, 2nd ed.; Glorieux, F.H., Pettifor, J.M., Jüppner, H., Eds.; Academic Press: Cambridge, MA, USA, 2012; pp. 9-37.

19. Workman, G.; Bradshaw, A.D. Chapter 19-Production and Purification of Recombinant Human SPARC, in Methods in Cell Biology; Mecham, R.P., Ed.; Academic Press: Cambridge, MA, USA, 2018; pp. 335-345.

20. Humphrey, E.L.; Morris, G.E.; Fuller, H. Valproate reduces collagen and osteonectin in cultured bone cells. Epilepsy Res. 2013, 106, 446-450. [CrossRef]

21. Cerilli, A.L.; Wick, M.R. Chapter 3-Immunohistology of Soft Tissue and Osseous Neoplasms, in Diagnostic Immunohistochemistry, 2nd ed.; Dabbs, D.J., Ed.; Churchill Livingstone: London, UK, 2006; pp. 65-120.

22. Heinegard, D.; Oldberg, A. Structure and biology of cartilage and bone matrix noncollagenous macromolecules. Faseb J. 1989, 3, 2042-2051. [CrossRef]

23. Jundt, G.; Termine, J.D.; Schulz, A. Osteonectin-a differentiation marker of bone cells. Cell Tissue Res. 1987, 248, 409-415. [CrossRef]

24. Badylak, S.F. The extracellular matrix as a scaffold for tissue reconstruction. Semin. Cell Dev. Boil. 2002, 13, 377-383. [CrossRef]

25. Hodde, J.P. Extracellular matrix as a bioactive material for soft tissue reconstruction. ANZ J. Surg. 2006, 76, 1096-1100. [CrossRef]

26. Spang, M.T.; Karen, C. Extracellular matrix hydrogel therapies: In vivo applications and development. Acta Biomater. 2018, 68, 1-14. [CrossRef] [PubMed]

27. Bradshaw, A.D.; Sage, E.H. SPARC, a matricellular protein that functions in cellular differentiation and tissue response to injury. J. Clin. Investig. 2001, 107, 1049-1054. [CrossRef] [PubMed]

28. Brekken, R.A.; Sage, E. SPARC, a matricellular protein: At the crossroads of cell-matrix communication. Matrix Boil. 2001, 19, 815-827. [CrossRef]

29. Bella, J.; Hulmes, D.J. Fibrillar Collagens. Subcell Biochem. 2017, 82, 457-490.

30. Mortimer, G.M.; Minchin, R.F. Cryptic epitopes and functional diversity in extracellular proteins. Int. J. Biochem. Cell Boil. 2016, 81, 112-120. [CrossRef]

31. Wong, S.L.; Sukkar, M.B. The SPARC protein: An overview of its role in lung cancer and pulmonary fibrosis and its potential role in chronic airways disease. Br. J. Pharmacol. 2016, 174, 3-14. [CrossRef]

32. Bonnans, C.; Chou, J.; Werb, Z. Remodelling the extracellular matrix in development and disease. Nat. Rev. Mol. Cell Boil. 2014, 15, 786-801. [CrossRef]

33. Rosset, E.M.; Bradshaw, A.D. SPARC/osteonectin in mineralized tissue. Matrix Boil. 2016, 52, 78-87. [CrossRef] 
34. Holland, P.W.H.; Harper, S.J.; McVey, J.H.; Hogan, B.L. In vivo expression of mRNA for the Ca++-binding protein SPARC (osteonectin) revealed by in situ hybridization. J. Cell Boil. 1987, 105, 473-482. [CrossRef]

35. Ghanemi, A.; Yoshioka, M.; St-Amand, J. Broken Energy Homeostasis and Obesity Pathogenesis: The Surrounding Concepts. J. Clin. Med. 2018, 7, 453. [CrossRef]

36. Müller, M.J.; Lagerpusch, M.; Enderle, J.; Schautz, B.; Heller, M.; Bosy-Westphal, A. Beyond the body mass index: Tracking body composition in the pathogenesis of obesity and the metabolic syndrome. Obes. Rev. 2012, 13, 6-13.

37. Goossens, G.H. The Metabolic Phenotype in Obesity: Fat Mass, Body Fat Distribution, and Adipose Tissue Function. Obes. Facts 2017, 10, 207-215. [CrossRef]

38. Després, J.-P.; Fias, F. Body Fat Distribution and Risk of Cardiovascular Disease. Circulation 2012, 126, 1301-1313. [CrossRef]

39. Bradshaw, A.D.; Graves, D.C.; Motamed, K.; Sage, E.H. SPARC-null mice exhibit increased adiposity without significant differences in overall body weight. Proc. Natl. Acad. Sci. USA 2003, 100, 6045-6050. [CrossRef]

40. Riedl, I.; Yoshioka, M.; Nishida, Y.; Tobina, T.; Paradis, R.; Shono, N.; Tanaka, H.; St-Amand, J. Regulation of skeletal muscle transcriptome in elderly men after 6weeks of endurance training at lactate threshold intensity. Exp. Gerontol. 2010, 45, 896-903. [CrossRef] [PubMed]

41. Melouane, A.; Yoshioka, M.; St-Amand, J. Extracellular matrix/mitochondria pathway: A novel potential target for sarcopenia. Mitochondrion 2019, 50, 63-70. [CrossRef] [PubMed]

42. Romani, P.; Brian, I.; Santinon, G.; Pocaterra, A.; Audano, M.; Pedretti, S.; Mathieu, S.; Forcato, M.; Bicciato, S.; Manneville, J.-B.; et al. Extracellular matrix mechanical cues regulate lipid metabolism through Lipin-1 and SREBP. Nature 2019, 21, 338-347. [CrossRef] [PubMed]

43. Sullivan, W.J.; Mullen, P.J.; Schmid, E.W.; Flores, A.; Momcilovic, M.; Sharpley, M.S.; Jelinek, D.; Whiteley, A.E.; Maxwell, M.B.; Wilde, B.; et al. Extracellular Matrix Remodeling Regulates Glucose Metabolism through TXNIP Destabilization. Cell 2018, 175, 117-132.e21. [CrossRef]

44. Song, H.; Guan, Y.; Zhang, L.; Li, K.; Dong, C. SPARC interacts with AMPK and regulates GLUT4 expression. Biochem. Biophys. Res. Commun. 2010, 396, 961-966. [CrossRef]

45. Omi, S.; Yamanouchi, K.; Nakamura, K.; Matsuwaki, T.; Nishihara, M. Reduced fibrillar collagen accumulation in skeletal muscle of secreted protein acidic and rich in cysteine (SPARC)-null mice. J. Veter-Med Sci. 2019, 81, 1649-1654. [CrossRef]

46. Riley, J.H.; Bradshaw, A.D. The Influence of the Extracellular Matrix in Inflammation: Findings from the SPARC-Null Mouse; Anat Rec: Hoboken, NJ, USA, 2019.

47. Gilmour, D.T.; Lyon, G.J.; Carlton, M.B.; Sanes, J.R.; Cunningham, J.M.; Anderson, J.R.; Hogan, B.L.; Evans, M.J.; Colledge, W.H. Mice deficient for the secreted glycoprotein SPARC/osteonectin/BM40 develop normally but show severe age-onset cataract formation and disruption of the lens. EMBO J. 1998, 17, 1860-1870. [CrossRef]

48. Swaminathan, S.S.; Oh, D.-J.; Kang, M.H.; Ren, R.; Jin, R.; Gong, H.; Rhee, U.J. Secreted Protein Acidic and Rich in Cysteine (SPARC)-Null Mice Exhibit More Uniform Outflow. Investig. Opthalmol. Vis. Sci. 2013, 54, 2035-2047. [CrossRef] [PubMed]

49. Sangaletti, S.; Tripodo, C.; Cappetti, B.; Casalini, P.; Chiodoni, C.; Piconese, S.; Santangelo, A.; Parenza, M.; Arioli, I.; Miotti, S.; et al. SPARC Oppositely Regulates Inflammation and Fibrosis in Bleomycin-Induced Lung Damage. Am. J. Pathol. 2011, 179, 3000-3010. [CrossRef] [PubMed]

50. Rempel, S.A.; Hawley, R.C.; Gutiérrez, J.A.; Mouzon, E.; Bobbitt, K.R.; Lemke, N.; Schultz, C.R.; Schultz, L.R.; Golembieski, W.; Koblinski, J.; et al. Splenic and immune alterations of the Sparc-null mouse accompany a lack of immune response. Genes Immun. 2007, 8, 262-274. [CrossRef]

51. Pichler, R.H.; Bassuk, J.A.; Hugo, C.; Reed, M.J.; Eng, E.; Gordon, K.L.; Pippin, J.; Alpers, C.E.; Couser, W.G.; Sage, E.H.; et al. SPARC is expressed by mesangial cells in experimental mesangial proliferative nephritis and inhibits platelet-derived-growth-factor-medicated mesangial cell proliferation in vitro. Am. J. Pathol. 1996, 148, 1153-1167.

52. Francki, A.; Motamed, K.; McClure, T.D.; Kaya, M.; Murri, C.; Blake, D.J.; Carbon, J.G.; Sage, E.H. SPARC regulates cell cycle progression in mesangial cells via its inhibition of IGF-dependent signaling. J. Cell. Biochem. 2003, 88, 802-811. [CrossRef]

53. Ghanemi, A.; St-Amand, J. Interleukin-6 as a "metabolic hormone". Cytokine 2018, 112, 132-136. [CrossRef] 
54. Xu, Y.; Zhang, Y.; Ye, J. IL-6: A Potential Role in Cardiac Metabolic Homeostasis. Int. J. Mol. Sci. 2018, 19, 2474. [CrossRef]

55. Qu, D.; Liu, J.; Lau, C.W.; Huang, Y. IL-6 in diabetes and cardiovascular complications. Br. J. Pharmacol. 2014, 171, 3595-3603. [CrossRef]

56. Erdogan, B.; Webb, D.J. Cancer-associated fibroblasts modulate growth factor signaling and extracellular matrix remodeling to regulate tumor metastasis. Biochem. Soc. Trans. 2017, 45, 229-236. [CrossRef]

57. Moriggi, M.; Giussani, M.; Torretta, E.; Capitanio, D.; Sandri, M.; Leone, R.; De Palma, S.; Vasso, M.; Vozzi, G.; Tagliabue, E.; et al. ECM Remodeling in Breast Cancer with Different Grade: Contribution of 2D-DIGE Proteomics. Proteom. 2018, 18, 1800278. [CrossRef] [PubMed]

58. Yuzhalin, A.E.; Lim, S.Y.; Kutikhin, A.; Gordon-Weeks, A.N. Dynamic matrisome: ECM remodeling factors licensing cancer progression and metastasis. Biochim. Biophys. Acta (BBA) Bioenerg. 2018, 1870, 207-228. [CrossRef] [PubMed]

59. Yang, M.; Liu, P.; Huang, P. Cancer stem cells, metabolism, and therapeutic significance. Tumor Boil. 2016, 37, 5735-5742. [CrossRef] [PubMed]

60. Lyssiotis, C.A.; Kimmelman, A.C. Metabolic Interactions in the Tumor Microenvironment. Trends Cell Boil. 2017, 27, 863-875. [CrossRef]

61. Ghanemi, A.; Yoshioka, M.; St-Amand, J. Secreted protein acidic and rich in cysteine and cancer: A homeostatic hormone? Cytokine 2020, 127, 154996. [CrossRef]

62. Irminger-Finger, I.; Kargul, J.; Laurent, G.J.; Laurent, G.J. Extra cellular matrix a modular soil for stem cells. Int. J. Biochem. Cell Boil. 2016, 81, 164. [CrossRef]

63. Murphy-Ullrich, J.E.; Sage, E.H. Revisiting the matricellular concept. Matrix Boil. 2014, 37, 1-14. [CrossRef]

(C) 2020 by the authors. Licensee MDPI, Basel, Switzerland. This article is an open access article distributed under the terms and conditions of the Creative Commons Attribution (CC BY) license (http://creativecommons.org/licenses/by/4.0/). 